GRADIATION\&APPLICATIONS

ISSN 2466-4294 (online) | rad-journal.org

Vol. 3 | Issue 3 | pp. 197-201, 2018

doi: 10.21175/RadJ.2018.03.033

Original research paper

\title{
ELECTROMAGNETIC FIELD EXPOSURE FROM TELECOMMUNICATION SOURCES IN AREAS WITH "SENSITIVE" BUILDINGS AND PLACES"
}

\author{
Iv. Topalova1, Ts. Shalamanova ${ }^{1^{* *}}$, V. Zaryabova1, M. Israel1,2 \\ ${ }^{1}$ National Centre of Public Health and Analyses, Sofia, Bulgaria \\ ${ }^{2}$ Medical University-Pleven, Pleven, Bulgaria
}

\begin{abstract}
There is a significant increase in the use of mobile communications services and it is expected that this growth will continue with the introduction of new generations of technology standards such as Long Term Evolution (LTE), for example. The exposure from environmental sources in urban areas is formed mainly by broadcasting antennas, and base stations for mobile communications. The large number of telecommunication sources placed in the urban areas provoked serious concerns about possible health effects, considering the exposure to electromagnetic fields (EMF). Particular attention has been paid to the so-called "critical" or "sensitive" areas around hospitals, schools, kindergartens, etc. Hence, there is a need of adequate exposure assessment of the electromagnetic field levels in some selected high populated urban areas especially around hospitals, schools, kindergartens to ensure that the power density levels are well below the prescribed threshold limits. The report presents an exposure assessment of electromagnetic field emitted by telecommunication sources (base stations) which has been performed at selected "sensitive" areas around hospitals, schools, kindergartens, located throughout Sofia. The study is conducted under the BGo7 Program: Public Health Initiatives with the financial support of the Norwegian Financial Mechanism 20092014 and the European Economic Area Mechanism, 2009-2014, entitled "Improving control and information systems in risk prevention and healthcare". Different methods of exposure assessments have been used: in-situ measurements (outdoor spot measurements of electromagnetic field values) using non-frequency selective and frequency selective measurement methods, as well as a broadband EMF monitoring for continuous measurement of the total EMF from all surrounding telecommunication sources that were also provided. The analyses of the measurement results suggest that the exposure levels to RF-EMFs are generally well below the reference levels defined by the national and European legislation. The electromagnetic field levels at the most studied locations are lower (up to 50\%) than the limit values according to the Bulgarian legislation and less than $1 \%$ of the limit values according to the European legislation for the frequency band about $900 \mathrm{MHz}$.
\end{abstract}

Key words: Base stations, electromagnetic fields, exposure assessment

\section{INTRODUCTION}

Lately, there has been a significant increase in the use of mobile communications services and this growth is expected to continue with the introduction of new generation technology standards. Respectively, the emission levels are different due to the new technical characteristics of the antennae, new infrastructure deployment, especially in the urban areas.

The large number of base stations in the populated areas provokes serious concerns and fears among the population about the influence of EMF on human health. Hence, there is a need of adequate exposure assessment of the electromagnetic field levels, including monitoring of EMF exposure in some selected heavily populated urban areas, especially around hospitals, schools, kindergartens to ensure that the power density levels are well below the prescribed threshold limits.

A study on EMF exposure assessment, conducted in Sweden, showed that LTE's average contribution to the total radio frequency exposure is less than $5 \%$. [1]

The results of other studies related to the measurement of electromagnetic field from base stations show that despite of the increasing number of base stations and deployment of additional mobile technology, the levels of electromagnetic exposure remain almost the same in public areas. [2]-[4]

\section{AIM}

The purpose of this report is to present and analyze the results of measurement and evaluation of electromagnetic exposure in selected areas of Sofia with the presence of "sensitive" buildings and places.

\footnotetext{
* This paper was presented at the Sixth International Conference on Radiation and Applications in Various Fields of Research (RAD 2018), Ohrid, Macedonia, 2018.

ts.shalamanova@gmail.com
} 
Iv. Topalova et al., Electromagnetic field exposure..., Rad. Applic., 2018, 3, 3, 197-201

\section{MATERIALS AND METHODS}

\subsection{Methods}

The measuring sites are selected according to Method of randomized selection of points for measurement and assessment of EMF in "sensitive buildings and places". This method requires preliminary information concerning the location of sensitive buildings and places such as: hospitals, healthcare facilities, schools, kindergartens, homes for medical and social care, leisure and recreation, playgrounds, etc. Information regarding EMF sources and their distribution is obtained after visual inspection of the investigated area. [5]

The locations of "sensitive buildings and locations" are defined for the administrative district of the respective municipality, and for each selected "sensitive" location, points for measuring and evaluating EMF values are selected.

The study covers 22 "sensitive" areas on the territory of Sofia.

The points of measurement are determined by visual inspection and survey of the area. The measurement points are selected to meet the "worst case" criterion in terms of exposure to the population closest building, direction of the emitting sector of the antenna system, how the electromagnetic energy falls to the place of measurement.

The measurements are performed according to the requirements of EN ISO 50492 "Basic standard for measuring the field strength of electromagnetic field related to human exposure near base stations" and EN ISO 50400 "Basic standard for demonstrating the conformity of fixed equipment for transmitting radio signals (110 MHz - $40 \mathrm{GHz}$ ) intended for use in wireless telecommunications networks with basic limitations or support levels relating to the exposure of the population to radio frequency electromagnetic fields in service", which are specialized international standards defining measurement methods, measurement systems, and post-processing of results for adequate exposure assessment in the vicinity of communication radiators.[6], [7]

For each monitored area, non- frequency selective and frequency selective measurement methods, as well as 24-hour monitoring of EMF values for estimating real-time exposure to EMF, are applied. For an integral exposure assessment, a non-frequency selective (broadband) method is used at all points defined by the cited methodology. This method is suitable for carrying out a cumulative assessment of EMF levels, i.e. pooling the contributions of all radio frequency sources in the spot to be measured. Broadband measurement has been used to indicate whether it is necessary to make a detailed (frequency analyses and 24-hour exposure monitoring) study of the field at a given point. At the points where the highest EMF value was measured, a selective (frequency analysis) method for detailed exposure estimation and information on the contribution of each transmitter in the total measured EMF at the metering point was applied. They also provide 24-hour monitoring by setting monitoring stations to collect real-time exposure data for the selected location.

\subsection{Measuring equipment}

For non-selective measurements Narda NBM-550 field strength meter, of NARDA Safety Test Solutions is used: with an EF1891 E field probe. Frequency range: from $3 \mathrm{MHz}$ to $18 \mathrm{GHz}$.

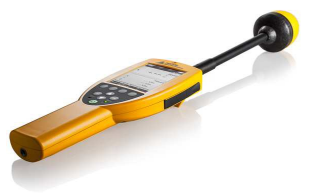

Figure 1. Narda NBM-550, NARDA Safety Test Solutions

For detecting, analyzing and localizing radio frequency (RF) signals, Interference and direction analyzer IDA-3106/102, NARDA Safety Test Solutions, has been used, with a 3100/13 active directional antenna set, operating frequency range $9 \mathrm{kHz}$ to $6 \mathrm{GHz}$.

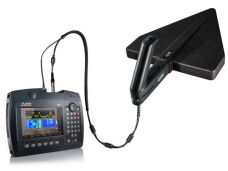

Figure 2. Interference and direction analyzer IDA-3106/102, NARDA Safety Test Solutions

For continuous 24-hour measurement of EMF values, NARDA Safety Test Solutions, NARDA AMB 8059 , with a $100 \mathrm{kHz}$ to $7 \mathrm{GHz}$ operating frequency band, were used.

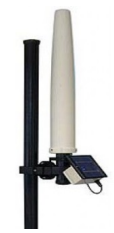

Figure 3. NARDA AMB 8059, NARDA Safety Test Solutions

\section{RESULTS AND DISCUSSION}

4.1. Non- frequency selective and frequency selective measurements

Frequency-selective analysis was performed in selected 22 areas of Sofia with the presence of "sensitive" buildings and locations.

For each "sensitive" area, measurement points are determined after a site inspection and survey. According to the above mentioned methodology for determining the point where a frequency-selective analysis was applied, each of the "sensitive" areas was scanned with broadband equipment for a total exposure assessment by a non frequency -selective method. 

points.

Figure 4 shows the locations of the measurement

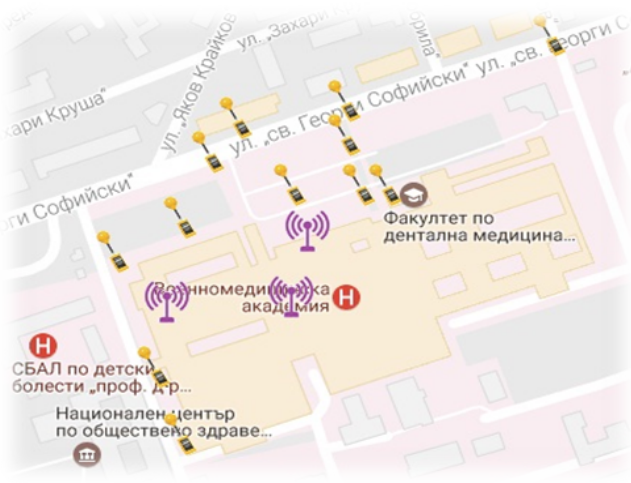

Figure 4. Location of measuring points in one of the selected "sensitive" areas

Figure 5 shows maximum power density values from broadband measurement for all 22 "sensitive" areas surveyed. Measurements are made using E field probe in frequency range from $3 \mathrm{MHz}$ to $18 \mathrm{GHz}$.

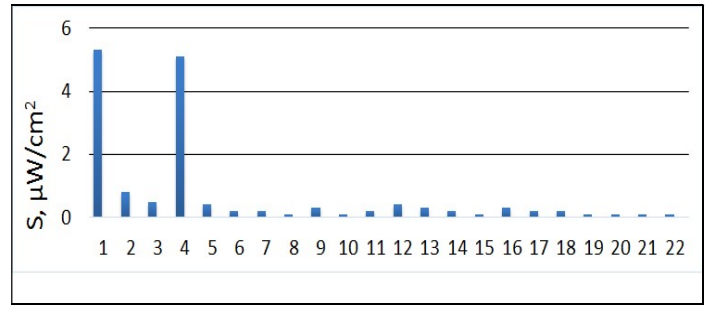

Figure 5. Maximum power density values at the investigated areas

In two areas the values of $5.1 \mu \mathrm{W} / \mathrm{cm}^{2}$ and $5.3 \mu \mathrm{W} / \mathrm{cm}^{2}$ were measured, which are different from the other with higher values of the measured power density. The analysis of the data showed that these higher values are due to the presence of more than one emitter at a distance of less than $100 \mathrm{~m}$ from the measurement point. The estimated expanded uncertainty is $41 \%$ (confidence level of $95 \%$ ).

These values are about $50 \%$ of the permissible value $\left(10 \mu \mathrm{W} / \mathrm{cm}^{2}-6.14 \mathrm{~V} / \mathrm{m}\right)$ according to the Bulgarian legislation, Ordinance No. 9/14.03.1991. [8]

A frequency-selective analysis has been applied where the maximum field value is measured. Frequency response scans were performed in the appropriate frequency sub-assemblies. The frequency range $450 \div 2200 \mathrm{MHz}$ has been investigated, and the overlapping method is used for more detailed processing of the spectrum. Spectrum mode is used in order to detect the signals in the investigated frequency range. Maximum (Max), average value (Avg) traces are used for initial classification of the nature of a signal.

Scope mode view of the investigated frequency range is presented in Fig. 6 .

Signals which interested us are isolated and directly transferred to the other operating modes for foundered analysis.

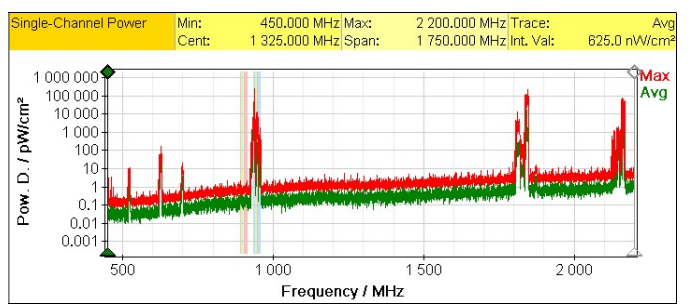

Figure 6. Spectrum view of the signals in the frequency range $450 \div 2200 \mathrm{MHz}$ in the region " 12 "

The following Figures 7 and 8 are illustrating the signal patterns of sub-divided frequency ranges.

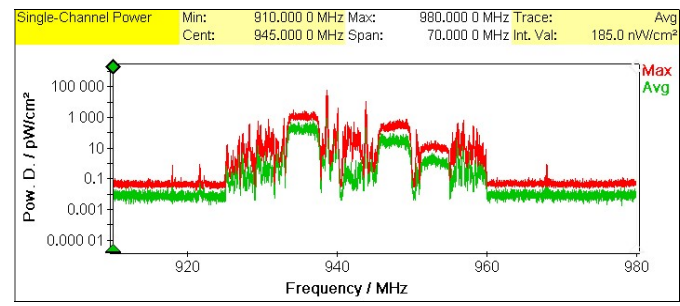

Figure 7. Spectrum view of the frequency range $910 \div 980 \mathrm{MHz}$ in the region " 12 ",

$\mathrm{RBW}=\mathbf{2 0} \mathrm{kHz}, \mathrm{SWT}=\mathbf{2 0} \mathrm{ms}$

Figure 7 shows that in the frequency band of $925 \div 960 \mathrm{MHz}$ in the region "12", DL GSM 900 and DL UMTS 900 channels are detected of three mobile operators.

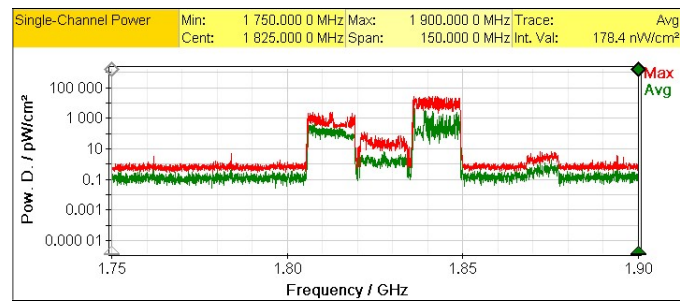

Figure 8. Spectrum view of the signal patterns in the frequency range $1750 \div 1900 \mathrm{MHz}$ the region “ 12 ", $\mathrm{RBW}=50 \mathrm{kHz}, \mathrm{SWT}=17 \mathrm{~ms}$

LTE emissions consist of specific signals at specific time-frequency allocations, known as Orthogonal Frequency Division Multiple Access (OFDMA).

If frequency information about the present LTE channels is not available the LTE downlink bandwidth is determined using spectrum mode. In this way the frequency information and LTE bandwidth can be best determined.

In the frequency band $1750 \div 1900 \mathrm{MHz}$, the main contribution is due to the transmission of four mobile operators with DL in the bands as follows: $(1805 \div 1820 \mathrm{MHz}, 1820 \div 1835 \mathrm{MHz}$, $1835 \div 1850 \mathrm{MHz}, 1865 \div 1880 \mathrm{MHz}$ ) (Figure 8).

In the $2100 \div 2200 \mathrm{MHz}$ frequency band UMTS channels of three mobile operators are detected ( 2125 $\div 2140 \mathrm{MHz}, 2140 \div 2155 \mathrm{MHz}, 2155 \div 2170 \mathrm{MHz}$ ).

Universal Mobile Telecommunications System (UMTS) uses a multiple access technique, where 
multiple users and the signaling are separated by different spreading codes (WCDMA - Wideband Code Division Multiple Access). By multiplication with the spreading code, the data signal is spread in the spectrum. The Primary Common Pilot Channel (P-CPICH) is the only permanent and formed more than $10 \%$ of the maximal power of the station. Due to the noise like signal characteristic with high crest factor, the RMS detector is used. The resolution bandwidth has to be chosen to $5 \mathrm{MHz}$. A slow mode which means very slow sweeping speed is used.

\subsection{Analysis of data from a continuous 24-hour measurement of real-time EMF levels}

EMF levels from telecommunication sources are constantly changing over time; therefore, adequate exposure estimation requires continuous measurement of exposure throughout the day and sometimes for several days. Data from EMF point measurements obtained by a non-selective and selective method are very indicative but do not give information about the dynamics of the electromagnetic field over time. It is very likely that the data from point measurements do not reflect the maximum EMF values at a specific location. With maximum system load, the so-called "high traffic" period, the EMF levels may be higher than the measured ones.

For a full exposure assessment, monitoring stations have been installed in the selected "sensitive" areas to the points determined by spot measurements to allow a continuous 24-hour measurement of EMF levels. All results are stored in built-in memory and by connection to a computer, data extraction and analysis are performed in real time, and after the measurement has been completed. The collected information has been reviewed, processed, analyzed and put into the EMF Source Register.

In this way, citizens and stakeholders have information about levels of exposure created by telecommunication facilities, base stations, radio and television stations, near schools, hospitals, buildings, etc.

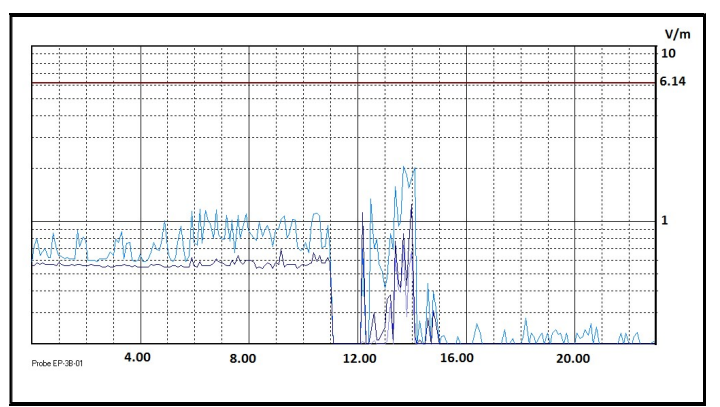

Figure 9. Data from a continuous 24-hour measurement of EMF levels by a monitoring station located near of a school, region " 15 "

Figure 9 shows the data from a continuous 24-hour measurement of EMF levels from a monitoring station located near a fence of a school. (Region "15"). Peak measured EMF values are about 1.0 - $1.5 \mathrm{~V} / \mathrm{m}$, equivalent to $0.3-0.6 \mu \mathrm{W} / \mathrm{cm}^{2}$ for "far field" and flat electromagnetic wave. The measured values are due to the fact that there are no telecommunication sources at a distance of less than $100 \mathrm{~m}$ from the installation site of the monitoring station.

As it is described above, two of the "sensitive" areas examined by spot measurements were found to have significantly higher field strengths than other regions. Figure 10 shows the data from a continuous 24-hour measurement of EMF levels from a monitoring station located near the park of the National Palace of Culture. The graph shows that the peak EMF values during the daylight are about $5 \mathrm{~V} / \mathrm{m}$, equivalent to $6.6 \mu \mathrm{W} / \mathrm{cm}^{2}$. In the hour range of $11 \mathrm{~h}$ p.m. to $5 \mathrm{~h}$ a.m., the values are reduced to about $3 \mathrm{~V} / \mathrm{m}$, which calculate in power density is equal to $2.4 \mu \mathrm{W} / \mathrm{cm}^{2}$. These results are due to the accumulation of multiple communication sources close to the monitoring point. The great number of business buildings and users of mobile communication also determines the higher EMF values during the day.

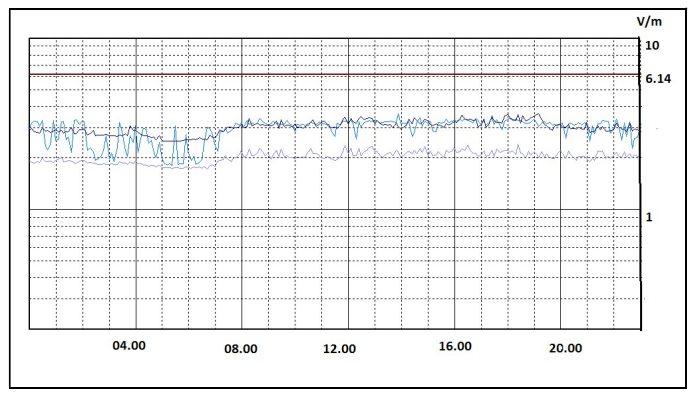

Figure 10. Data from a continuous 24-hour measurement of EMF levels by a monitoring station, region " 4 "

\section{CONCLUSION}

The analysis of the measurement results and the evaluation of the electromagnetic exposure in the 22 investigated "sensitive" areas have shown the following: the measured values of EMF are within the maximum permissible levels according to the national legislation. In case of location of large number of communication transmitters in one place, the levels of $\mathrm{EMF}$ are up to $50 \%$ of the maximum permissible values (10 $\mu \mathrm{W} / \mathrm{cm}^{2}$ ) according to the national legislation for general population. Taking into account the uncertainty, the total quantity will be close to the limit, regarding national legislation.

The measured values at two of the investigated regions are less than $1 \%$ of the reference levels according to the Council recommendation for the frequency range around 900 MHz. [8], [9]

The applied method of randomly selected points for measuring and evaluating EMFs in "sensitive buildings and locations" is informative and applicable for the purposes of monitoring and control.

\section{REFERENCES}

1. J. T. Rowley, K. H. Joyner, "Comparative international analysis of radiofrequency exposure surveys of mobile communication radio base 
stations," J. Expo. Sci. Environ. Epidemiol., vol. 22, no 3, pp. 304 - 315, May-Jun. 2012.

DOI: $10.1038 /$ jes.2012.13

PMid: 22377680

PMCid: 3347802

2. W. Joseph, L. Verloock, F. Goeminne, G. Vermeeren, L. Martens, "Assessment of general public exposure to LTE and RF sources present in an urban environment," Bioelectromagnetics, vol. 31, no 7, pp. 576 - 579, Oct. 2010.

DOI: $10.1002 /$ bem.20594

PMid: 20607741

3. Ts. Shalamanova at al., "Results of Measurements of Electromagnetic Fields around Base Stations for Mobile Communication in Bulgaria," in Proc. $9^{\text {th }}$ Nat. Conf. Biomedical Physics and Engineering, Bulgaria, 2004, pp. 129 - 134

4. M. Ivanova, Ts. Shalamanova, "Measurements of $\mathrm{RF}$ radiation around base stations for mobile communication in Bulgaria," J. Environ. Prot. Ecol., vol. 6, no. 2, pp. 328 - 336, Jan. 2005. Retrieved from: https://23fcge25-a-b7egb206-ssites.googlegroups.com/a/jepe-journal.info/jepejournal/vol-6-no-2/V6N2328-3362005.pdf; Retrieved on: Aug. 12, 2018

5. M. Israel, Iv. Topalova, Ts. Shalamanova, M. Ivanova, V. Zaryabova, "Methods for selection of measurement points in urban areas with high density of EMF sources and such with "sensitive places and buildings," Journal of Biomedical and Clinical Research, vol. 8, no. 1, suppl. 1, 2015. Retrieved from: https://ephconference.eu/reposito ry/countries/Abstract Book Vol 8-1Suppl.pdf; Retrieved on: Aug. 10, 2018

6. Basic standard for the in-situ measurement of electromagnetic field strength related to human exposure in the vicinity of base stations, EN ISO 50492:2008, Jan. 31, 2009.
Retrieved from: https://shop.bsigroup.com/Produc tDetail/?pid=000000000030268384;

Retrieved on: Aug. 12, 2018

7. Basic standard on measurement and calculation procedures for human exposure to electric, magnetic and electromagnetic fields $(\mathrm{O} \mathrm{Hz}-$ $300 \mathrm{GHz}$ ), EN ISO 50413:2008, Jan. 1, 2008.

Retrieved from: https://infostore.saiglobal.com/en -gb/standards/i-s-en-50413-2008-

873723_SAIG_NSAI_NSAI_2077363/;

Retrieved on: Aug. 12, 2018

8. Министерство на здравеопазването. (14.03.1991). Наредба № 9 от 14.03.1991 2. га за пределно допустими нива на електромагнитни полета в населени територии $u$ определяне на хигиеннозащитни зони около излъчващи обекти. (Ministry of Health. (Mar. 14, 1991). Ordinance No. 9 from 14.03.1991 on the limit values of electromagnetic fields in populated areas and the determination of hygienic-protective zones around radiating objects.)

Retrieved from: http://econ.bg/Нормативни-актове/Наредба-qот-14-03-1991-г-за-пределно-допустими-нивана-електромагнитни-полета-в-населениl.1 i.128561 at.5.html;

Retrieved on: Aug. 13, 2018

9. The Council of the European Union. (Jul. 12, 1999). 1999/519/EC Council Recommendation of 12 July 1999 on the limitation of exposure of the general public to electromagnetic fields (o $\mathrm{Hz}$ to $30 \mathrm{GHz}$ ). Retrieved from: https://www.anacom.pt/streaming 1999-519-

CE.pdf? contentId $=33252 \&$ field $=$ ATTACHED FILE Retrieved on: Aug. 13, 2018 